\title{
Trans-sphincteric anorectoplasty for rectovestibular fistula
}

\section{Sarah Magdy Abdelmohsen', Mohamed Abdelkader Osman ${ }^{2}$, Osama Abdullah Abdul Raheem³, Hussien Ali Mustafa Abdulmotaleb ${ }^{4}$, Basel Magdy Abdelmohsen ${ }^{5}$}

1. Pediatric surgery, Aswan University hospital, Egypt.

2. Headmaster of pediatric surgery, Assiut University hospital, Egypt.

3. General surgery, Aswan University hospital, Egypt.

4. General surgery, Dean of the Faculty of Medicine, Aswan university hospital

5. Ain Shams University, Egypt.

\section{ARTICLE INFO}

\section{Corresponding Author:}

\section{Sarah Magdy Abdelmohsen \\ Pediatric surgery, Aswan University hospital, Egypt.}

Keywords: Rectovestibular fistula (RVF), Trans-sphincter anorectoplasty (TSARP), Transfistula Anorectplasty (TFARP), sphincter-saving anorectoplasty (SSARP), Posterior anal transposition, Anorectal malformation (ARM) in a female.

\begin{abstract}
Introduction:

Imperforate anus with recto vestibular fistula is the most common form of the imperforate anus in females and is an intermediate type of this disease, which is treated surgically(2). Generally, patients with vestibular fistulas have good functional results when treated by fistula transposition (8).
\end{abstract}

\section{Materials and methods:}

This was a prospective study did from January 2016 to January 2017. We included all female with age range from (25 days -12years old) diagnosed as a rectovestibular fistula (RVF) operated by single stage TSARP, at pediatric surgery units of Assiut and Aswan university hospitals. The functional results, cosmetic appearance and postoperative complication for each case after treatment were evaluated in patients for 3-6 months.

\section{Results:}

The total numbers of cases are 22 cases from rural areas of Upper Egypt, $(36.36 \%)$ of patient's fathers and mothers are relatives and have associated anomalies. (50\%) of cases are complaining of recurrent attack of constipation. (45.5\%) of cases developed wound infection at the neoanal site. 7 cases are now more than 3years old, 6 of those 7 cases achieved voluntary bowel control and toilet trained and have good (4-5 points) wing spread score. One case less than 3 years old also achieved voluntary bowel control and toilet trained and has good ( 5 points) wing spread score.

\section{Conclusion:}

Trans-sphincter anorectoplasty (TSARP) is easy to perform with reasonable operative time, good cosmetic and functional outcome. Separation of the rectum from the posterior wall of the vagina is the most delicate step of the operation, takes place under direct vision. Constipation is an essential problem in patients that can be managed by laxatives. Meticulous postoperative wound care is essential.

\section{INTRODUCTION}

Rectovestibular fistula (RVF) is the most frequent anorectal malformation (ARM), constituting approximately $25 \%$ of ARM in females (1). The close proximity of the ectopic anus with the vulva and the stenosed opening seen in a large majority of cases necessitates some form of surgical correction. A variety of surgical procedures like posterior anal transposition synonymously known as trans-sphincter anorectoplasty (TSARP), anterior or posterior sagittal anorectoplasty with or without a diverting colostomy have been done (2). Optimal surgical repair would be easy to assess minimum dissection to spare pelvic nerves and guide the rectal pouch through the muscles of continence and intact sphincter. Despite a 
better understanding of embryology, the anatomy and the physiology of continence, the management of children born with RVF continues to be a surgical challenge and is still fraught with numerous complications (3-5).

The purpose of present study was to see the effectiveness of Trans-fistula Anorectplasty (TFARP) also, synonymously known as trans-sphincter anorectoplasty (TSARP) which was required minimal dissection without interruption of perineal body and perineal skin with an aim to improving the functional and cosmetic results in patients with RVF.

\section{Materials and methods:}

This was a prospective study did from January 2016 to January 2017. We included all female from upper Egypt with age range from (25 days -12years old) diagnosed as a rectovestibular fistula (RVF) operated by single stage TSARP operated at pediatric surgery units of Aswan and Assiut university hospitals. None of the patients had a preliminary colostomy. All cases had a well-formed perineum \& gluteal region. All cases were done by consultant pediatric surgeons. Ethical permission was taken from the ethical committee. An informed written consent for primary one stage procedure was taken.

\section{Preoperative preparation:}

Detailed history and clinical examination were carried out including the perineum, buttocks, spine and other systems for associated anomalies. Routine blood investigations such as CBCs, renal function tests, serum electrolytes followed by abdominal ultrasound scans were done to assess renal anomalies. X-ray whole body and spine was done to exclude other bony anomalies. An echocardiography was also performed where indicated. Fistulogram with lateral views was done to show the levels of the rectal pouch and to look for any other communication. The child was allowed clear fluids by mouth until 4 hours before the surgery.

Rectal washouts with normal saline four times in a day, beginning 48 hours pre-operatively. Also, the Rectal fistula was washed with 20-25 cc/kg warm normal saline + povidone Iodine in a concentration of $1: 10$ for $10 \mathrm{~min}$ while the patient was anesthetized before commencement of surgery (on table preparation).

\section{Surgical technique:}

The choice of anesthesia was general with a caudal block. Intravenous $\quad 3^{\text {rd }}$ generation cephalosporin, amoxicillin and clavulanic acid and metronidazole were given at induction. Surgery was performed in lithotomy position after catheterizing the bladder. A Proposed anal site was determined by the anal dimple and confirmed by the use of a muscle stimulator, and the landmark to the neoanal site was taken by simple suture. Peri-fistula traction sutures were taken incorporating the wall of the fistula to facilitate retraction during dissection. Dilute $(0.001 \%)$ adrenaline solution was injected under the mucosa of the fistula to facilitate its separation from the rectovaginal septum and to minimize bleeding. A circumferential incision was made on the mucosa of the fistula and a submucosal plane is entered.

The submucosal dissection is carried upward, carefully separating the common rectovaginal septum up to the cervix anterior and posterior up to the sacral promontory. No incision was made over the perineum and perineum was kept intact. At this level, the full thickness of the distal rectum was reached. The neoanal site with its external sphincter muscle complex was previously landmarked with simple stitch, A cruciate incision of about $1 \mathrm{cms}$ was made at that site, and the opening created in the external sphincter complex, through which mobilized rectum was pulled. The narrowed distal part of the rectum was excised and fixed to the deep muscle complex, with vicryl 4'0. Anoplasty was done with 12 stitches with 5'0 vicryl; the neoanus allowed 10/12 sized Hegar's dilator. The site of the primary fistula was closed in layers with 5'0 vicryl interrupted stitches. The rectum was packed with Vaseline gauze after surgery which was removed on the next day.

\section{Postoperative care:}

Feeding is started on the first postoperative day. An indwelling urinary catheter placed at operation remains for approximately 3 days postoperatively. The mother was instructed to apply povidone iodine solution over the operated wound and neoanus several times a day, and after each bowel movement, the antibiotic ointment was applied three to four times a day. Intravenous antibiotics were continued for up to the 5 th postoperative day. A majority of the patients were discharged on the 6th postoperative day unless complications occurred, when the stay was prolonged. Anal dilatations were started on 14th post-operative day with Hegar's dilator, taught to the parents who were asked to regularly dilate for two times a day for two weeks, once daily for one month, twice a week for one month, once a week for one month, and then once a week for three months.

\section{Follow-up schedules:}

Follow-up schedules are a14th postoperative day, and continue every 2 weeks up to 3 monthes. During each visit, the following points are noted: appearance, site and size of the neoanus, a condition of the wound. Data regarding early (up to 1 month) complications like wound infection, wound dehiscence, skin excoriation, and delayed (3 months to 6 months) complications like mucosal prolapse, fistula formation, stenosis was collected. Information about whether scheduled dilatation was followed, bowel habits, continence, soiling and an unsatisfactory cosmetic outcome was gathered. Anal dilatation carried out with appropriate size Hegar dilator after lubrication with 2\% lignocaine jelly, dilatation procedure were demonstrated to the parents for future dilatation at home, with local made metallic anal dilator calibrated with proper size Hegar dilator, by researcher according to Pena's anal dilatation schedule. In this study, all the patients came for follow-up, as per our schedule.

\section{Assessment of fecal continence}

Anocutaneous reflex and anal squeeze on per rectal digital examination were performed for younger children who had not attained the age of continence (less than 3 years). For children older than 3 years, modified Wingspread Scoring (6) was adopted to evaluate fecal continence. The outcome was designated as "good," "fair," or "poor."

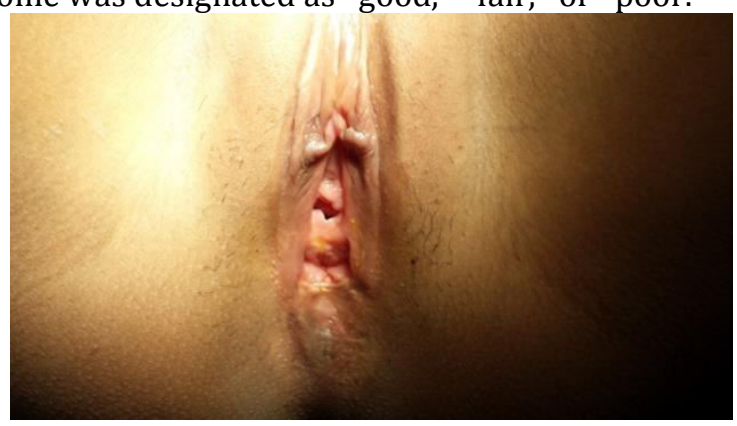


Fig 1: Vestibular anus in 12 years old female.

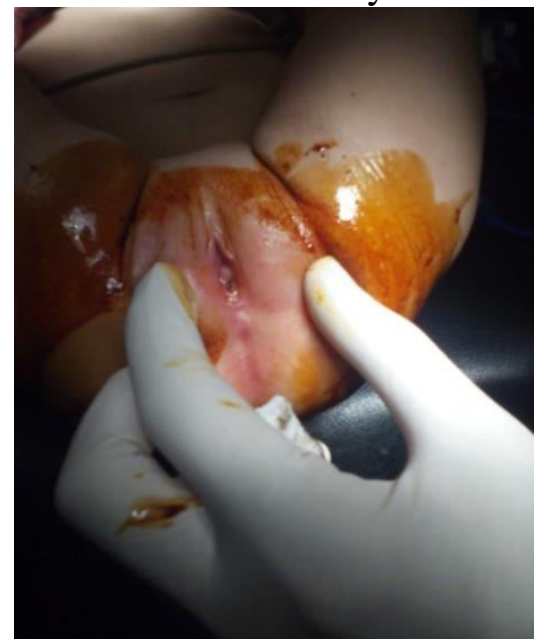

Fig 2: Vestibular anus in 3 months female neonate.

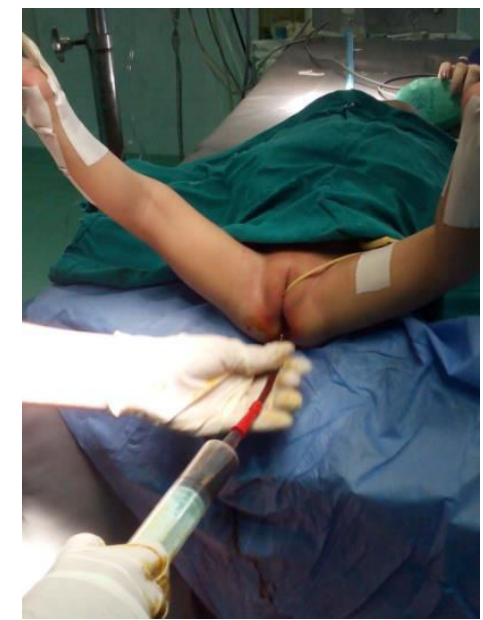

Fig 3: on table preparation, warm normal saline + povidon Iodine in a concentration of 1:10

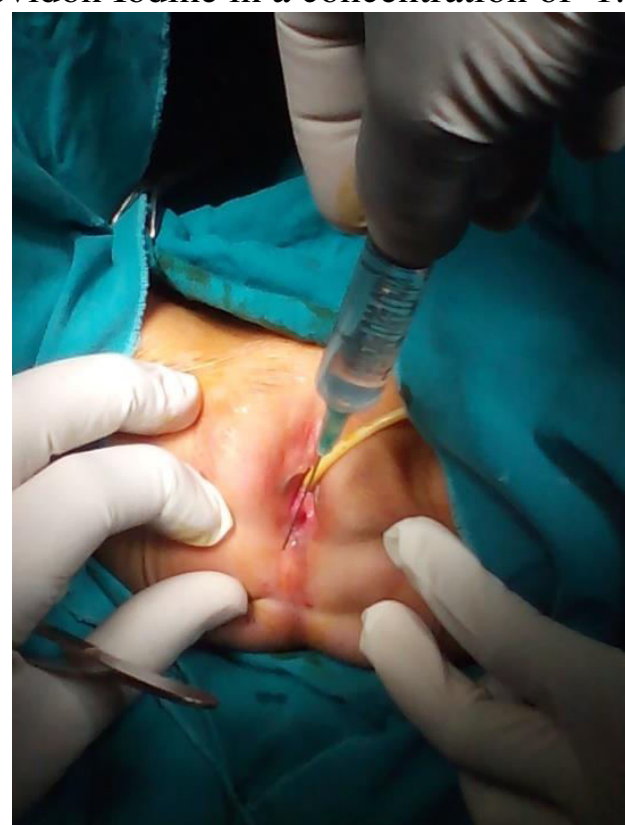

Fig 4: Dilute (0.001\%) adrenaline solution was injected under the mucosa of the fistula.

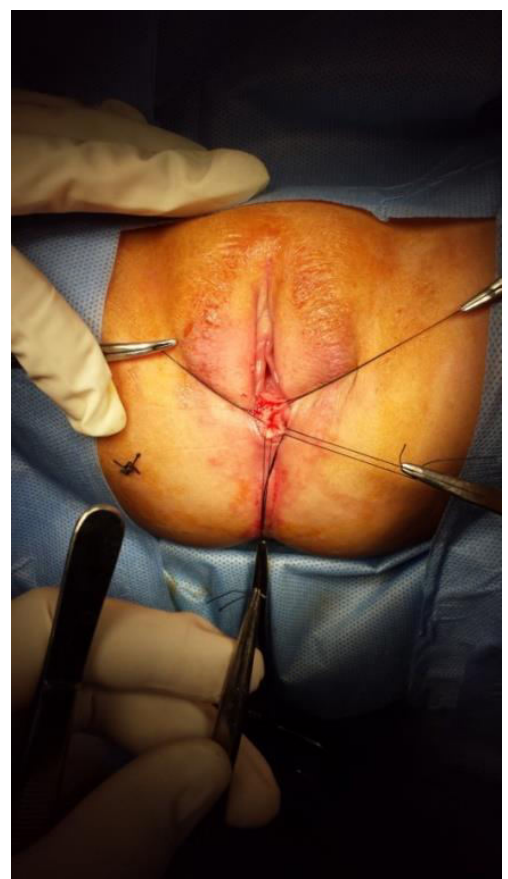

Fig 5: Peri-fistula traction sutures incorporating the wall of the fistula.

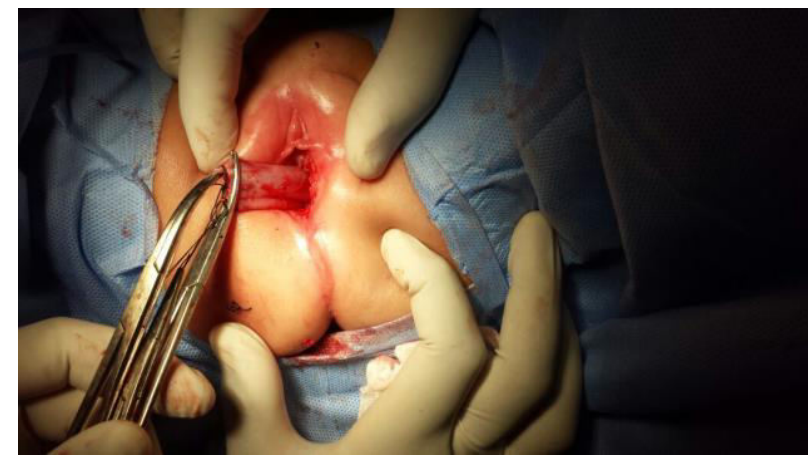

Fig 6: mobilization of fistula along with rectum.

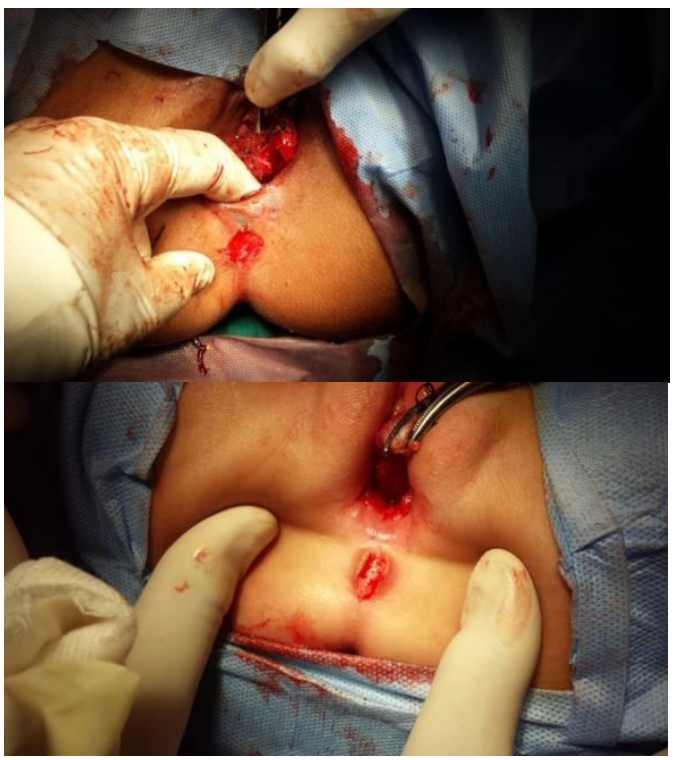

Fig7: Incision was given at the proposed anus site. 


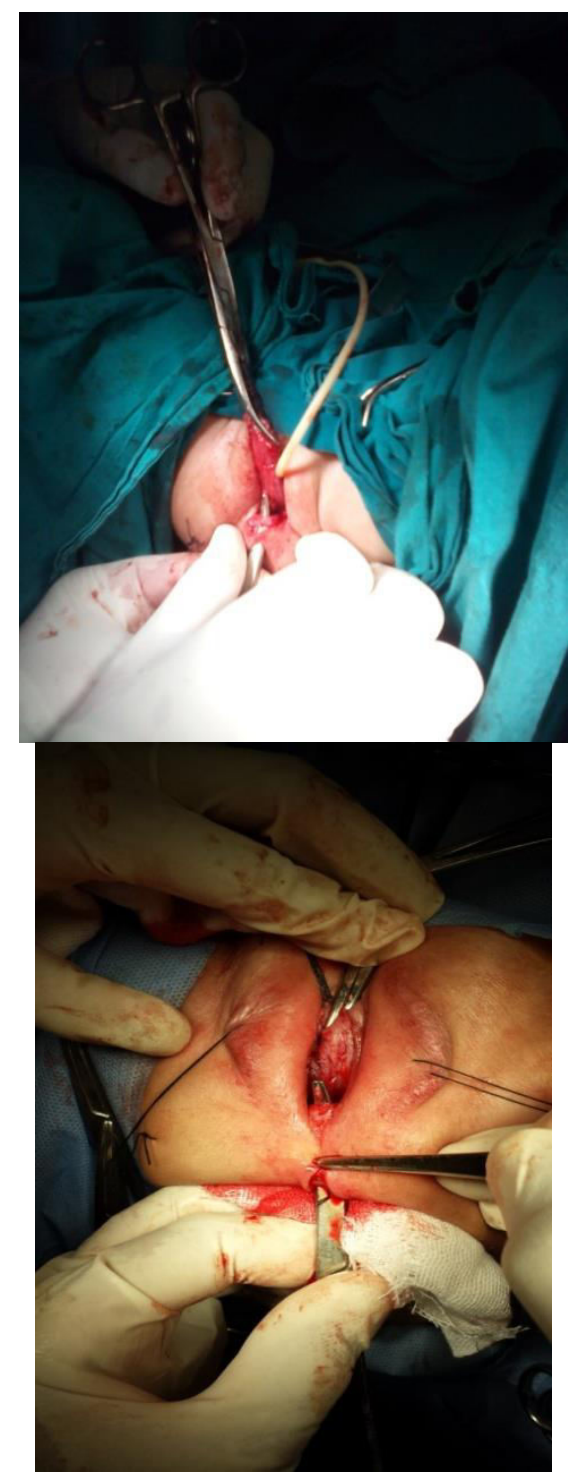

Fig 8: opening created in the external sphincter complex, through which mobilized rectum will be pulled.

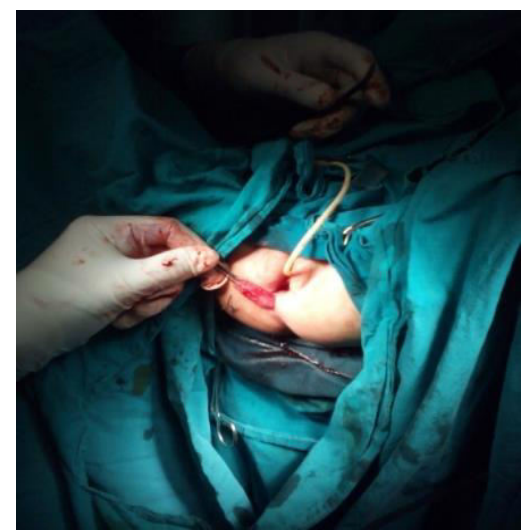

Fig 9: Pull of the rectum through the external sphincter.

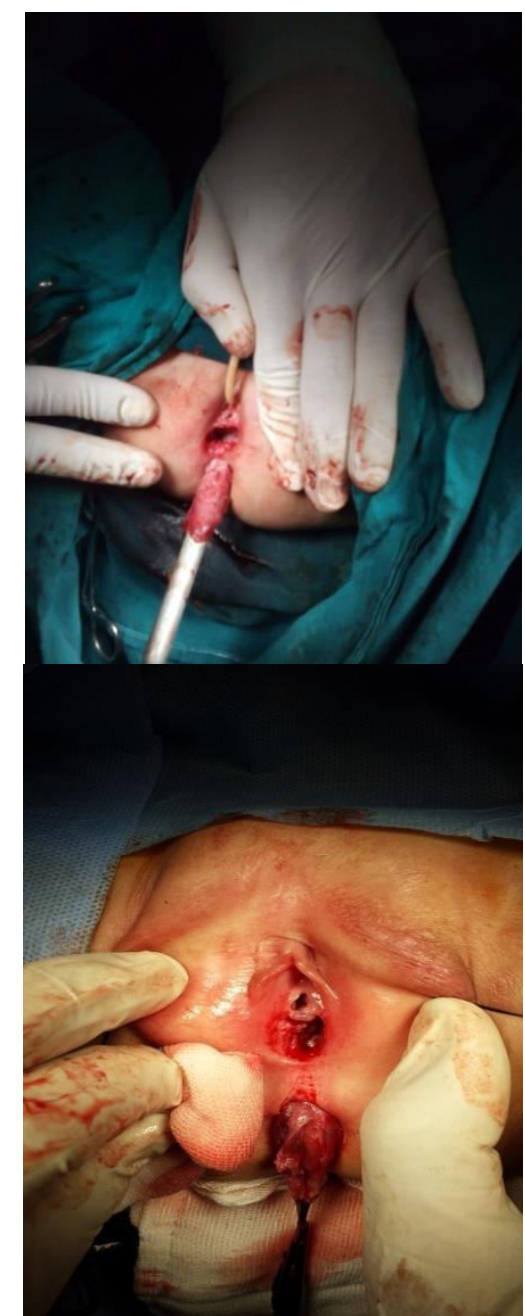

Fig 10: perineal defect at previous anal site.

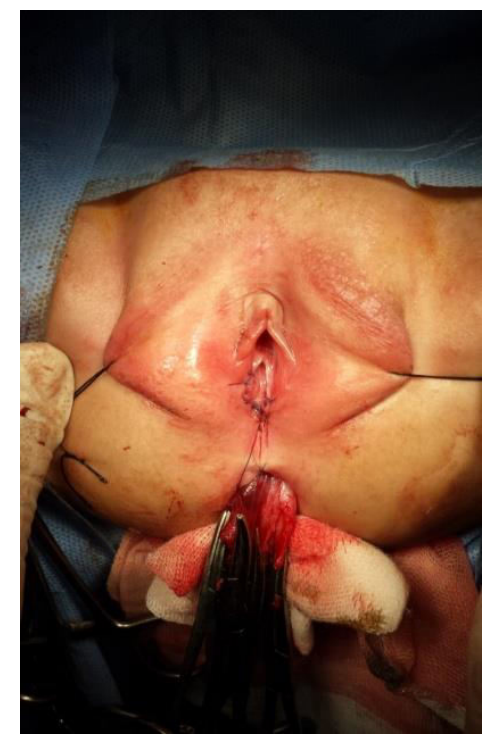




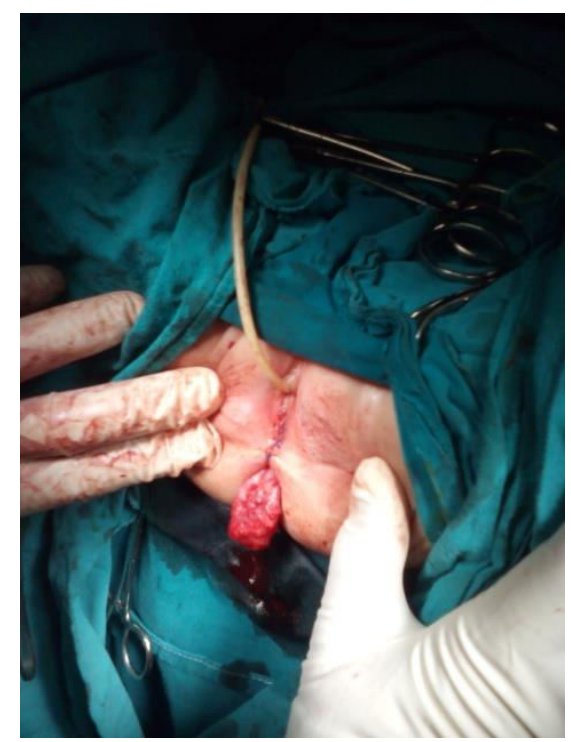

Fig 11: Repaired perineal body.

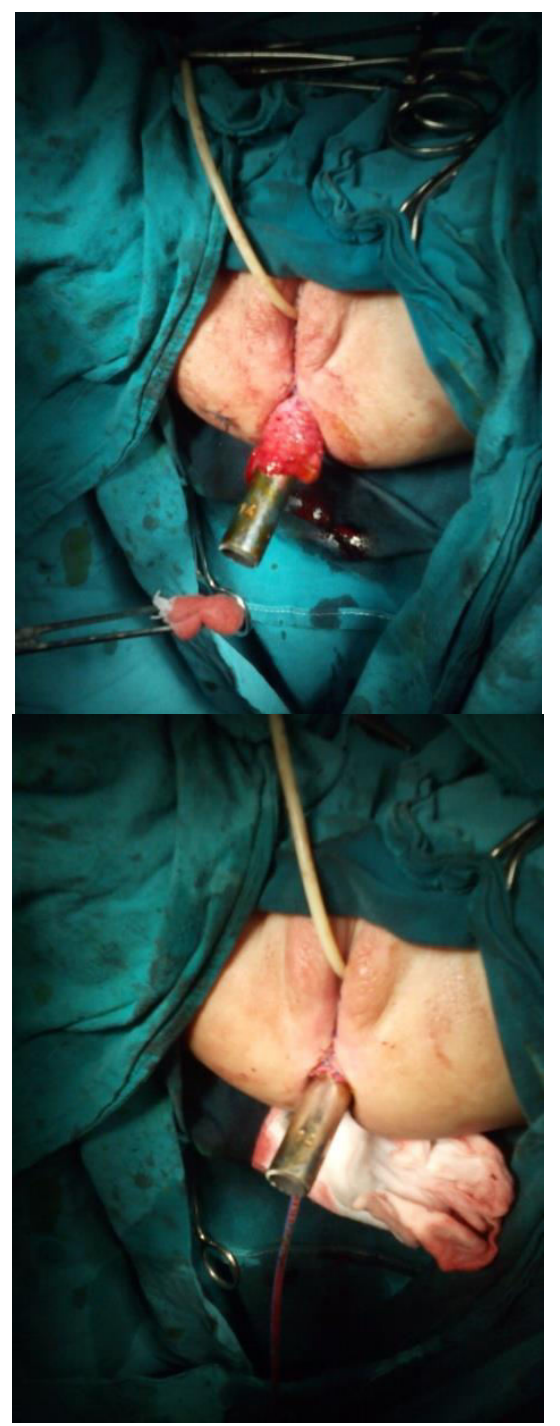

Fig 12: The narrowed distal part of the rectum was excised and fixed to the deep muscle complex.

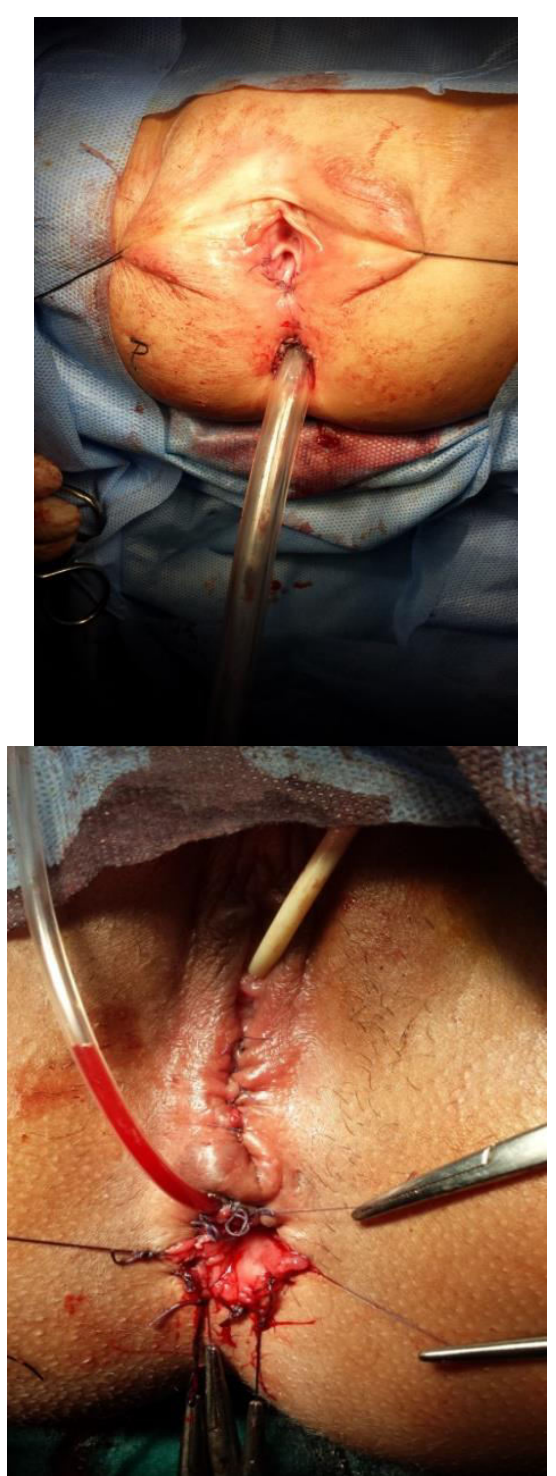

Fig 13: Immediate post operative view.

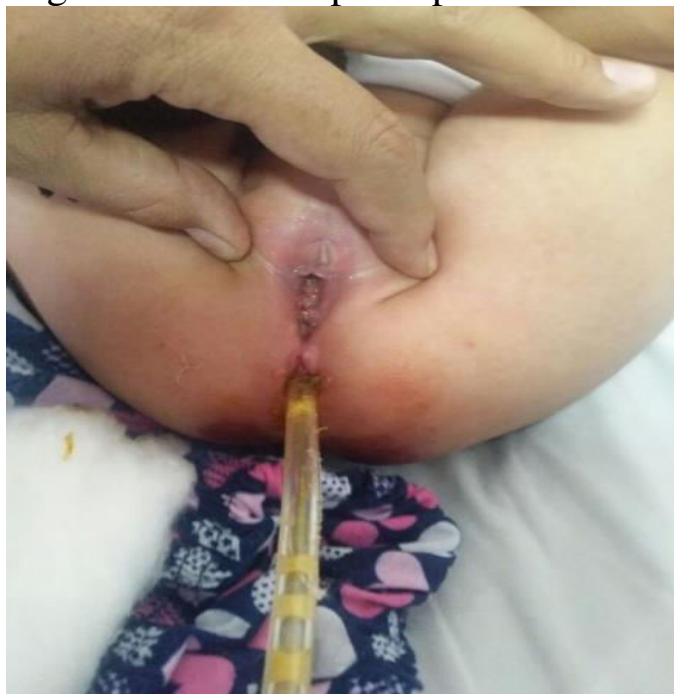


Trans-sphincteric anorectoplasty for rectovestibular fistula

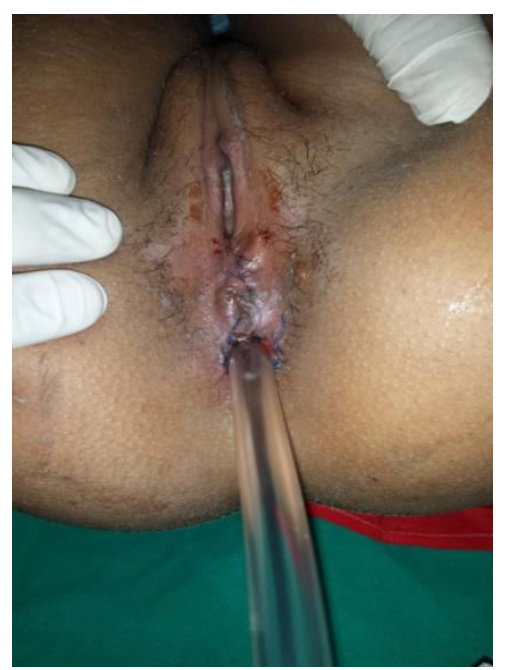

Fig 14: 2 week's postoperative view.

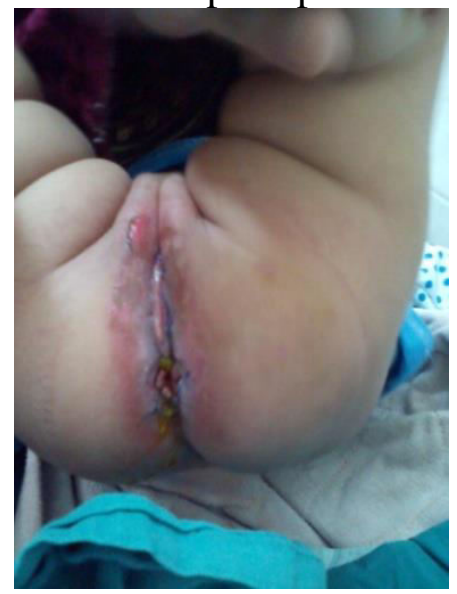

Fig 15: skin excoriation to one of the cases 1 month postoperative.

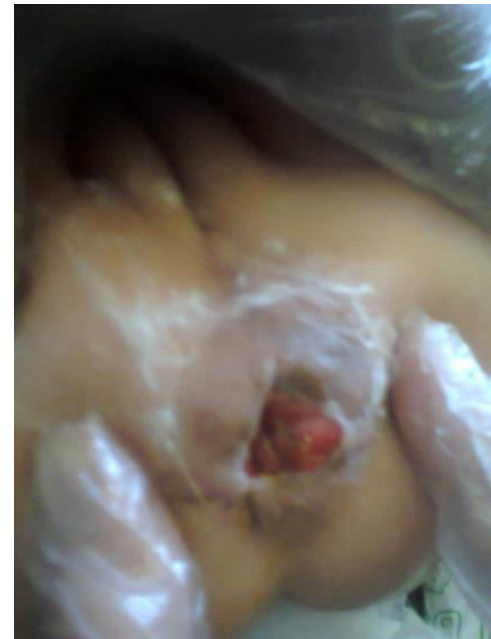

Fig 16: mucosal prolapsed few months postoperative.

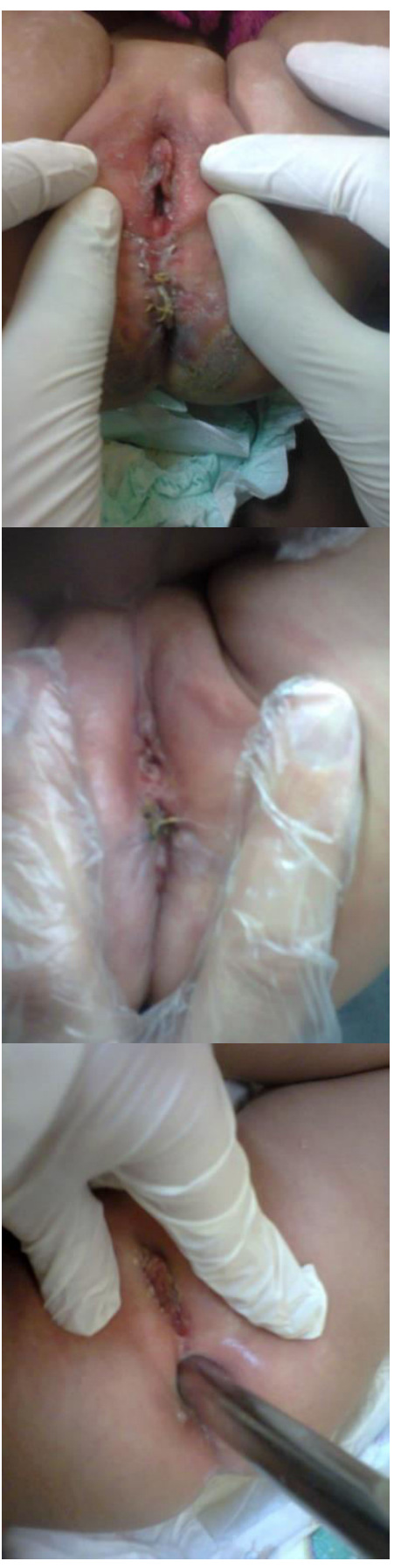

\begin{tabular}{|l|c|c|}
\hline \multicolumn{1}{|c|}{ Age at operation } & Frequency & Percent \\
\hline Less than 1 year & 12 & 54.6 \\
From 1 year up to 2 years & 7 & 31.8 \\
More than 2 years up to 3 years & 0 & 0 \\
More than 3 years & 3 & 13.6 \\
Total & 22 & 100.0 \\
\hline
\end{tabular}




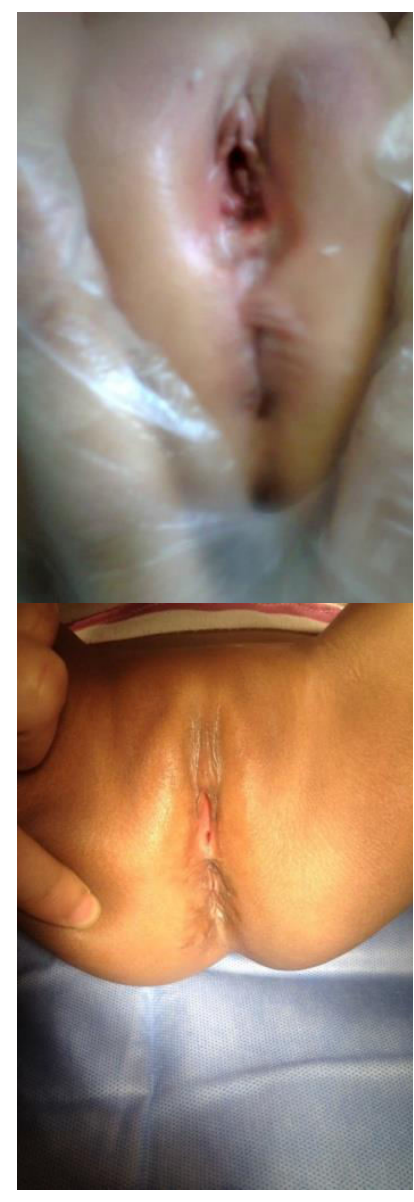

\begin{tabular}{|c|c|c|c|}
\hline \multicolumn{2}{|c|}{ Associated anomalies } & frequency & percentage \\
\hline cardiac anomalies & $\begin{array}{c}\text { VSD } \\
\text { ASD + Vertebral scoliosis }\end{array}$ & 2 & 9.1 \\
\hline Renal anomalies & $\begin{array}{c}\text { right pelviureteric junction } \\
\text { obstruction and } \\
\text { hydronephrosis + } \\
\text { hydrocephalous }\end{array}$ & 1 & 4.5 \\
\hline vertebral anomalies & ASD+ Vertebral scoliosis & 1 & 4.5 \\
\hline limb anomalies & $\begin{array}{c}\text { congenital right tibia } \\
\text { deficiency }\end{array}$ & 1 & 4.5 \\
\hline Other GIT anomalies & congenital megacolon & 2 & 9.1 \\
\hline Ear anomaly & congenital earlobe cleft & 1 & 4.5 \\
\hline Laryngeal anomaly & congenital laryngeal web & 1 & 4.5 \\
\hline \multicolumn{2}{|c|}{ mother and father relation } \\
\hline
\end{tabular}

Fig 16: few months' postoperative view to different cases.

\section{Results:}

The total numbers of cases are 22 cases between 25 days and 12 years old from rural areas of Upper Egypt, 20 cases of them are operated at Assiut university hospital, the other 2 cases are operated at Aswan university hospital, from January 2016 up to January 2017, and all cases are operated by experienced pediatric surgeons.

The mean age of the operated patient was 2 years (range: 25 days-12 years), the mean weight was $9.95 \mathrm{kgs}$ (range: $3 \mathrm{kgs}-45 \mathrm{kgs}$ ). As most of our patient went to hospital asked for interventions at late age group because of low socioeconomic status of their relatives.

\section{Table 1: Age at Operation in the Study Group}

8 cases (36.36\%) of patient father and mother are relatives, 14 cases $(63.64 \%)$ are not relatives.

Also, 8 cases $(36.36 \%)$ of a patient have associated anomalies, 14 cases $(63.64 \%)$ are not associated with any other anomalies.

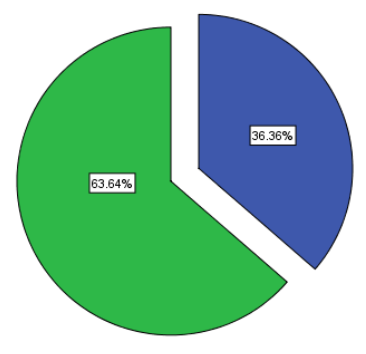

associated anomalies

$\underset{\substack{\text { Eves } \\ \text { mos }}}{\operatorname{mos}}$

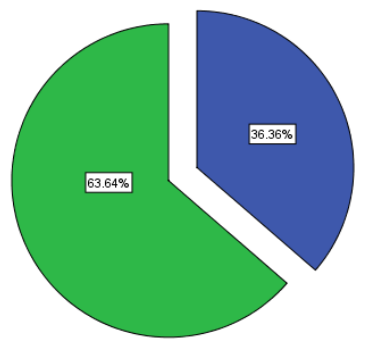

The associated anomalies of the patients are shown in Table 2.

Table 2: Associated anomalies in the study group

$(\mathrm{N}=\mathbf{2 2})$

2 cases of these associated anomalies group have multiple congenital anomalies:

Case A: vestibular anus + atrial septal defect (ASD) + vertebral scoliosis.

Case B: vestibular anus + right pelviureteric junction obstruction and hydronephrosis + hydrocephalous. 
Trans-sphincteric anorectoplasty for rectovestibular fistula

\begin{tabular}{|c|c|c|c|c|c|c|c|}
\hline Age group & $\mathrm{N}$ & Voluntary bowel control & $L \backslash E$ & $\begin{array}{c}\text { Bowel } \\
\text { movement } \backslash \text { day }\end{array}$ & $\begin{array}{l}\text { Anal } \\
\text { soiling }\end{array}$ & $\begin{array}{l}\text { Recurrent } \\
\text { constipation }\end{array}$ & $\begin{array}{l}\text { Abdominal } \\
\text { distension }\end{array}$ \\
\hline Less than 1 year & 3 & $\begin{array}{r}\text { Not achieved, not toilet } \\
\text { trained }\end{array}$ & $\begin{array}{l}\text { Yes1 } \\
\text { No } 2\end{array}$ & $2-4$ & $\begin{array}{c}\text { Yes } 2 \\
\text { No1 }\end{array}$ & $\begin{array}{l}\text { Yes1 } \\
\text { No } 2\end{array}$ & $\begin{array}{l}\text { Yes } 1 \\
\text { No } 2\end{array}$ \\
\hline $\begin{array}{r}\text { From 1year to less } \\
\text { than } 2 \text { years }\end{array}$ & 8 & $\begin{array}{r}\text { Not achieved, not toilet } \\
\text { trained }\end{array}$ & $\begin{array}{l}\text { Yes } 6 \\
\text { No2 }\end{array}$ & $2-3$ & $\begin{array}{l}\text { Yes } 2 \\
\text { No } 6\end{array}$ & $\begin{array}{l}\text { Yes } 3 \\
\text { No } 5\end{array}$ & No8 \\
\hline $\begin{array}{r}\text { From 2years to less } \\
\text { than 3year }\end{array}$ & 4 & $\begin{array}{r}1 \text { achieved, toilet trained. } \\
3 \text { Not achieved, not toilet } \\
\text { trained }\end{array}$ & Yes 4 & $1-2$ & $\begin{array}{l}\text { Yes } 1 \\
\text { No3 }\end{array}$ & Yes 4 & $\begin{array}{l}\text { Yes } 2 \\
\text { No } 2\end{array}$ \\
\hline More than 3 year & 7 & $\begin{array}{r}6 \text { achieved, toilet trained. } \\
1 \text { Not achieved, not toilet } \\
\text { trained }\end{array}$ & Yes 7 & 1 & $\begin{array}{l}\text { Yes } 3 \\
\text { No } 4\end{array}$ & $\begin{array}{l}\text { Yes } 3 \\
\text { No } 4\end{array}$ & No7 \\
\hline
\end{tabular}

The mean preoperative fasting hours was 10 hours. The mean preoperative rectal wash numbers were 2 times. The mean operative time was 53 minutes $\left(\mathrm{SD}_{-}+11\right) .1$ patient patients with recurrent fistula, postoperative anal abscess and stenosis spent a more hospital stay time.

\begin{tabular}{|c|c|c|c|c|c|c|c|c|c|c|c|}
\hline $\begin{array}{l}\text { Age groups } \backslash \\
\text { complication }\end{array}$ & frequency & $\begin{array}{l}\text { Recurrent } \\
\text { constipation }\end{array}$ & $\begin{array}{l}\text { Woun } \\
\text { d } \\
\text { infecti } \\
\text { on }\end{array}$ & $\begin{array}{c}\text { Skin } \\
\text { excor } \\
\text { iatio } \\
n\end{array}$ & $\begin{array}{c}\text { Anal } \\
\text { absc } \\
\text { ess }\end{array}$ & $\begin{array}{l}\text { Anal } \\
\text { sten } \\
\text { osis }\end{array}$ & $\begin{array}{l}\text { Abdomi } \\
\text { nal } \\
\text { Distensi } \\
\text { on }\end{array}$ & $\begin{array}{c}\text { Recur } \\
\text { rent } \\
\text { fistul } \\
\text { a }\end{array}$ & $\begin{array}{l}\text { Muco } \\
\text { sal } \\
\text { prola } \\
\text { pse }\end{array}$ & $\begin{array}{l}\text { Anterio } \\
r \\
\text { Displac } \\
\text { ed } \\
\text { anus }\end{array}$ & $\begin{array}{l}\text { Vaginal } \\
\text { bleeding }\end{array}$ \\
\hline $\begin{array}{r}\text { Less than } 1 \\
\text { year }\end{array}$ & 3 & $\begin{array}{l}\text { Yes } 1 \\
\text { No } 2 \\
\end{array}$ & $\begin{array}{l}\text { Yes } 2 \\
\text { No } 1 \\
\end{array}$ & No3 & No3 & No3 & $\begin{array}{l}\text { Yes } 1 \\
\text { No } 2 \\
\end{array}$ & No3 & No3 & No3 & No3 \\
\hline $\begin{array}{r}\text { From 1year to } \\
\text { less than } 2 \\
\text { years } \\
\end{array}$ & 8 & $\begin{array}{l}\text { Yes3 } \\
\text { No5 }\end{array}$ & $\begin{array}{l}\text { Yes2 } \\
\text { No6 }\end{array}$ & $\begin{array}{l}\text { Yes1 } \\
\text { No7 }\end{array}$ & No8 & No8 & No8 & $\begin{array}{l}\text { Yes1 } \\
\text { No7 }\end{array}$ & $\begin{array}{l}\text { Yes1n } \\
\text { o7 }\end{array}$ & No 8 & $\begin{array}{l}\text { Yes1 } \\
\text { No7 }\end{array}$ \\
\hline $\begin{array}{l}\text { From 2years to } \\
\text { less than 3year }\end{array}$ & 4 & $\begin{array}{l}\text { Yes4 } \\
\text { No2 }\end{array}$ & $\begin{array}{l}\text { Yes2 } \\
\text { No2 }\end{array}$ & $\begin{array}{l}\text { Yes1 } \\
\text { No3 }\end{array}$ & No4 & $\begin{array}{c}\text { Yes } \\
1 \\
\text { No3 } \\
\end{array}$ & $\begin{array}{l}\text { Yes2 } \\
\text { No2 }\end{array}$ & No4 & No4 & $\begin{array}{l}\text { Yes1 } \\
\text { No3 }\end{array}$ & No4 \\
\hline $\begin{array}{r}\text { More than } 3 \\
\text { year }\end{array}$ & 7 & $\begin{array}{l}\text { Yes3 } \\
\text { No4 }\end{array}$ & $\begin{array}{l}\text { Yes4 } \\
\text { No3 }\end{array}$ & $\begin{array}{l}\text { Yes4 } \\
\text { No3 }\end{array}$ & $\begin{array}{c}\text { Yes } \\
3 \\
\text { No4 }\end{array}$ & $\begin{array}{c}\text { Yes } \\
2 \\
\text { No5 }\end{array}$ & No7 & $\begin{array}{l}\text { Yes1 } \\
\text { No6 }\end{array}$ & $\begin{array}{l}\text { Yes1 } \\
\text { No6 }\end{array}$ & No7 & No7 \\
\hline $\begin{array}{c}\text { Total } \\
\text { frequency }\end{array}$ & 22 & 11 & 10 & 6 & 3 & 3 & 3 & 2 & 2 & 1 & 1 \\
\hline Percentage & & $50 \%$ & $45.5 \%$ & $\begin{array}{c}27.3 \\
\%\end{array}$ & $\begin{array}{c}13.6 \\
\%\end{array}$ & $\begin{array}{c}13.6 \\
\%\end{array}$ & $13.6 \%$ & $9.1 \%$ & $9.1 \%$ & $4.5 \%$ & $4.5 \%$ \\
\hline
\end{tabular}

suffered vaginal wall tear during separation of a rectal wall from the vaginal wall was repaired immediately by $6 / 0$ vicryl with postoperative wound infection and recurrent fistula to a previous anal site also with rectovaginal fistula as stool was coming from the previous anal opening and from the vagina at the $3^{\text {rd }}$ postoperative days. Another case had an iatrogenic thermal injury to the skin of the buttocks near the neoanal site and relieved by conservative treatment and continues dressing.

1 case suffered from postoperative vaginal bleeding (12 hours) postoperative and stopped by vaginal and rectal packing for 24 hours.

10 cases (45.5\%) developed wound infection at the neoanal site, 7 of these infected cases relieved by conservative treatment, where 3 cases $(13.6 \%)$ suffered from posterior anal abscess and had drainage under general anesthesia. 2 cases of those abscess drainage developed anal stenosis with one case of previous neoanal site infection, all these 3 cases (13.6\%) of anal stenosis had dilatation under general anesthesia with Hegar's dilators.

2 cases (9.1\%) suffered from recurrent fistula, one of these 2 cases had intraoperative vaginal wall tear and repaired, the other case had postoperative wound infection, the fistula appear on the $3^{\text {rd }}$ postoperative days. Redo operative intervention did with fistulectomy with covering pelvic colostomy, after 3 months pelvic colostomy closure did.
7 cases of 22 cases are now 3years old or older, 6 of those 7 cases achieved voluntary bowel control and toilet trained and had good (4-5 points) wing spread score. The last one, not toilet trained and had a fair (3.5 points) of wing spread score. 3 cases of these 7 cases had a recurrent attack of constipation and infrequent anal soiling.

The younger children have bowel pattern as per age, though do not pass in the toilet except for one case from the age group more than 2 years but less than 3 years which achieved voluntary bowel control and toilet trained and had good (5 points) wing spread score., the others cases had satisfactory anal contraction on stroking the perianal skin, good anal grip on per rectal examination except for 4 cases with poor Anocutaneous reflex and anal squeeze on per rectal examination. Table 2 shows the bowel habits of all the patients.

Table 3: Bowel habits of the patients according to age.

$\mathrm{L} \backslash \mathrm{E}=$ Anocutaneous reflex and anal squeeze on per rectal examination.

$\mathrm{N}=$ frequency of the cases.

11 cases of 22 cases (50\%) are complaining of recurrent attack of constipation; while 8 cases (36.4\%) are complaining of infrequent anal soiling.

Table 4: The frequency and the percentage of postoperative complication according to age groups (5-6 months postoperative). 


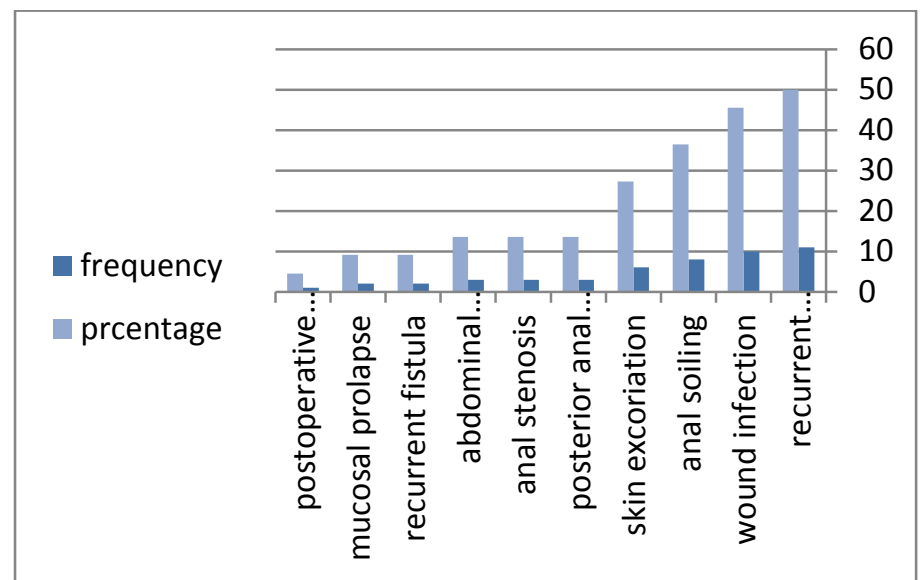

Bar chart 1: show percentage and frequency of postoperative complication.

The cosmetic outcome was satisfactory except for 2 cases (9.1\%) developed mucosal prolapse and needed musectomy.

$86.4 \%$ of the parents (19 cases) were satisfactory about the cosmetic appearance and operative intervention.

\section{Discussion:}

ARVF is the commonest form of ARM in girls and is associated with the best prognosis (7). Generally, patients with vestibular fistulas have good functional results when treated by fistula transposition (8). It is estimated that $93 \%$ of patients with ARVF will develop voluntary bowel movements (7).

The goal of anorectoplasty is to anatomically reconstruct the malformation to achieve fecal continence without damaging the nervi erigents and to have an aesthetic appearance of the neo-anus(9).TSARP is considered more acceptable with regards to a surgical outcome and aesthetic appearance of perineum as there is no visible scar mark in the perineum and strength of perineum is good as there is no interference of pelvic diaphragm and Reconstruction of a perineal body with opposition vestibular and perineal wound was performed (9).

Trans-fistula anorectoplasty (TFARP) and sphincter-saving anorectoplasty (SSARP) (2), this procedure is almost identical to TSARP trans-sphencter anorectoplasty procedures (10-11).

Traditionally, ARMs were reconstructed with a protective colostomy because of the fear of wound healing and subsequent loss of anal sphincter complex with the risk of impairment of future continence. The belief that a protective colostomy may prevent wound infection is questionable (12). Although some surgeon believed that the procedure with colostomy reduces immediate postoperative complications but has no significant influence on the function or site of the anus $(8,13)$. The primary advantages of performing anorectoplasty without a colostomy are the avoidance of colostomy-related complications and multi-staged surgeries $(14,15)$.

Regarding posterior vaginal injury, in our series 1 case $(4.5 \%)$ had posterior vaginal wall injury during dissection which was repaired immediately by $6 / 0$ vicryl with postoperative recurrent fistula at the $3^{\text {rd }}$ postoperative day. Alkhaffaf series there were $2(2.73 \%)$ patients out of 73 had posterior vaginal wall injury during dissection which was repaired immediately without postoperative complication (16). while in J shaheed series, there were 4 (20\%) vaginal wall injury (17), and it was only one case in Akshay et al (18).

Operation time in our series was between minimum time 40 minutes and maximum time was 75 minutes, mean operation time (53min), while the mean time was (60 $\mathrm{min})$ in Alkhaffaf series (16). The mean time was (76.5min) in J shaheed (17), it was (68min) in upadhyaya (19). Ashrarur reported the mean operation time was 81.2 minutes (20). Pratap A et al reported mean operating time $85 \mathrm{~min}$ (21). Mean hospital stay in our series was 7days while in J shaheed was 6.95days (17), in Ashrarur series was 6 days (20), Akshay et al was found 5 days mean hospital stay (18). Pratap A et al mean hospital stay was 5 days (21). It was 4.4 days in upadhyaya (19) and Just 3 days in Alkhaffaf series (16).

The lack of any skin incision in TFARP either anterior or posterior to the neo-anus leads to an excellent cosmetic result and completely circumvents the risk of wound dehiscence in this critical region (11).

In different reports of single-stage surgery, wound infection rate ranged from $0 \%(19,21)$ to $5.7 \%-10.6 \%$ $(7,12,22,23,20,17)$. In our series, the wound infection rate is $45,5 \%$ (10 cases) may be due to bad hygiene to this region from low educational level and low socioeconomic state of patient relatives.

We reported 3cases $(13.6 \%)$ of anal stenosis which were put on schedule of dilatation first at hospital (dilation under general anesthesia performed first then with local lignocaine ointment at follow-up period) then at home by their parents according to pena dilatation schedule, while upadhyaya series were 2cases (5\%) with anal stenosis (19). Pratap et al reported moderate anal stenosis developed in 1 patient (21). Alkhaffaf reported 5 cases (6.84\%) of anal stenosis (16).

Minimal constipation (G1-2) was observed in 11 cases $(50 \%)$ and was managed by laxatives. Henien reported postoperative functional constipation in $47 \%$ of patients with the anteriorly placed anus and 50\% in cases of vestibular fistula (11). Yeung and Kiely reported intractable constipation in $28 \%$ of their patients (24). Alkhaffaf reported $12(16.4 \%)$ patients with constipation (16). Upadhyaya reported 6 cases $(15 \%)$ with constipation (19). Ibrahim et al reported 3(12\%) cases of constipation (25).

Several authors report excellent continence ranging from $90.5-100 \%$ were continent $(7,11,20,22,23)$. In other series, continent scores were excellent or good among 58.3\%, $72 \%$ and fair in $20 \%(19,26)$. In our study, 7 patients have 
attained the age of continence and 6 cases (85.7\%) are having a good score, the last one, not toilet trained and had a fair (3.5 points) of wing spread score. The rest are having bowel habits as per their age with one case from the age group more than 2 years but less than 3 years achieved voluntary bowel control and toilet trained and having a good score.

TFARP thus provides satisfactory functional and cosmetic results with a normally situated anal opening.

\section{Conclusion:}

Trans-sphincter anorectoplasty (TSARP) is easy to perform with reasonable operative time, good cosmetic and functional outcome. Separation of the rectum from the posterior wall of the vagina is the most delicate step of the operation, takes place under direct vision. It has the advantages of being performed as one rather than three stages; it can be performed in infants as well as adults. Constipation is an essential problem in patients that can be managed by laxatives. Meticulous post-operative wound care is essential to prevent postoperative wound infection and its drawback.

\section{References:}

1-Pena A (1995) Anorectal malformations. Semin Pediatr Surg 4:35-47

2- Pena A, Levitt MA. Anorectal Malformations In: Grosfield JL, O'Neil JA, Fonkalsrud EW, Coran AG, editors. Pediatric Surgery. 6 th ed. Philadelphia: Mosby Elsevier; 2006. p. 1566-89.

3-Yazbeck S, Lucks FI, St-vil D (1992) Anterior perineal approach and three flap anorectoplasty for imperforate anus: optimal reconstruction with minimal destruction. J Pediatr Surg 27:190-195.

4-Templeton J, O’Neil J (1986) Anorectal malformations. In Welch KJ, Randolph JG, Ravitch MM, et al., editors, Pediatric Surgery, 4th Edition, Chicago, Year Book Medical

Publishers, 1022-1035

5- Rintala R, Mildh L, Lindalh H (1992) Fecal continence and quality of life in adult patients with an operated low anorectal malformations. J Pediatr Surg 27:902-905.

6-Moore SW (1996) Clinical outcome and long-term quality of life after surgical correction of Hirschsprung's disease. J Pediatr Surg 31:1496-1502.

7-Kumar B, Kandpal DK, Sharma SB, Agarwal LD, Jhamariya VN. Single-stage repair of vestibular and perineal fistulae without colostomy. J Pediatr Surg. 2008; 43: $1848-52$.

8- Saxena N, Bhattacharyya CN (1981) Perineal anal transplant in low anorectal anomalies. Surgery 90:464467.

9-Shi SD: Perineal skin bridge and levator muscle preservation in neutral sagittal anorectoplasty(NSARP) for vestibular fistula. Peditr Surg Int. 21:711-714, 2005.
10-Partap A, Tiwari A, Kumar A, Adhikary S, Singh SN, Paudel BH, et al. Sphincter saving anorectoplasty (SSARP) for the reconstruction of Anorectal malformations. BMC Surg 2007;24: 7-20.

11-Heinen FL. The surgical treatment of low anal defects and vestibular fistulas. Semin Pediatr Surg 1997;6: 204-16.

12- Caroline F, Aronson DC. Anterior or posterior anorectoplasty without colostomy for low type anorectal malformation: how to get a better outcome? J Pediatr Surg. 2010; 45: 1505-8.

13- Pena A. Imperforate anus and cloacal malformations. In: Keith W Ashcraft, editor. Pediatric Surgery. 3rd ed. Philadelphia: W.B. Saunders Company; 2000; p. 473-92.

14- Pena A, Hong A. Advances in the management of anorectal malformations. Am J Surg. 2000; 180:370-6.

15- Pena A, Migotto-Krieger M, Levitt MA. Colostomy in anorectal malformations: a procedure with serious but preventable complications. J Pediatr Surg. 2006; 41:74856.

16- Humam S. Alkhaffaf. Experience of Transfistula (TFARP) Repair for Congenital Recto-Vestibular Fistula. Global Journal of HUMAN SOCIAL SCIENCE: I Surgeries and Cardiovascular System Volume 14 Issue 2 Versions 1.0 Year 2014.

17- J shaheed suhrawardy. Transfistula Anorectoplasty (TFARP): Better Surgical Technique for the Management of Vestibular Fistula. Med M edcoll vol.4 No.1, June 2012.

18-Akshay P, Yadav RP, Shekhar VC, Singh A, Sen R. One stage correction of Rectovestibular fistula by transfistula anorectoplasty. J, World surg vol. 2007; 31(9):1-3.

19-Upadhyaya VD, Gangapadhyay AN, Pandey A, Kumar V, Sharma SP, Gopal SC, et al. Single-stage repair of rectovestibular fistula without opening the fourchette. J Pediatr Surg 2008; 43: 775-9.

20-Ashrarur Rahman Mitul, $\quad \underline{\mathrm{K}} \mathrm{M} \mathrm{N}$ Ferdous, Md. Shahjahan, and Jaglul Gaffar Khan.Trans-Fistula Anorectoplasty (TFARP): Our Experience in the Management of Anorectovestibular Fistula in Neonates. I Neonatal Surg. 2012 Jul-Sep; 1(3): 36.

21- Pratap A, Yadav RP, Shakya VC, Agrawal CS, Singh SN, Sen R. One-stage correction of recto-vestibular fistula by trans-fistula anorectoplasty (TFARP). World J Surg. 2007; 31:1894-7.

22- Demirbilek S, Ataurt HF. Anal transposition without colostomy: functional results and complications. Pediatric Surgery Int. 1999; 15: 221-3.

23- Menon P, Rao KLN. Primary anorectoplasty in females with common anorectal malformations without colostomy. J Pediatr Surg. 2007; 42: 1103-06.

24- Yeung CK, Kiely EM: Low anorectal anomalies:a critical appraisa. Pediatr Surg Int. 6:333-335, 1991.

25- Ibrahim Ali Ibrahim, Mohamd Korany, Samir A Ammar: One Stage Posterior Anal Transposition for low and Intermediate Aanorectal Anomalies in Females, Annals of 
Trans-sphincteric anorectoplasty for rectovestibular fistula

Pediatric Surgery, Vol3, No 2, April 2007 PP 92-96.

26- Moore TC. Advantages of performing the sagittal anoplasty operation for imperforate anus at birth. J Pediatr Surg. 1990; 25:276-7. 